\title{
Use Rodents as an Indicator of Environmental Pollution
}

\author{
Abd El Aleem Saad Soliman Desoky* \\ Department of Soil Science and Resource Conservation, National University of Lesotho, Lesotho
}

*Corresponding author: Abd El Aleem Saad Soliman Desoky, Plant protection Department (Agricultural Zoology), Faculty of Agriculture, Sohag University, Egypt.
Received Date: May 17, 2019

Published Date: June 13, 2019

\section{Abstract}

Human is one of the biggest factors that cause pollution in the environment at the local or global level. At the local level, the impact of man is confined to the small environment surrounding it. On the global level, the effect of human pollution of the atmosphere resulting in global climate change.

Therefore, rodents can be used as a biological indicator to assess the damage caused to the environment as a result of exposure to pollution factors that cause imbalance in the environment and affected by humans, plants and animals.

Keywords: Atmosphere; Biggest factors; Environment surrounding; Human pollution; Global level

\section{Introduction}

There is a great deal of concern regarding the hazard potential of human exposure to toxic substances and carcinogens as well as infectious agents in the environment. For monitoring purposes fish are well established with regard to aquatic pollution. However, for the human environment, mammalian species might be considered more relevant.

As the various types of rats are one of the most common animals sharing human habitants, they are natural candidates. In the present study, numbers of such wild rats were trapped in the metropolis of Bangkok and country regions of Thailand for comparison of lesions in the liver and lung which might provide indicators of carcinogens or other hazardous agents in the environment.

Glutathione S transferase P form positive foci could be detected in livers, comparable to the laboratory rat case, but without any significant link to site of capture. In contrast, fatty liver and inflammation/cirrhosis were significantly more frequent in animals from the metropolis. Parasite infection also tended to be more prevalent, along with leptospirosis. Inflammatory change was similarly found in the lungs but without any variation between the city and countryside groups. These results suggest that wild rats could be employed as monitors of environmental agents of toxicological significance [1].
This research is concerned with the inventory of the most important methods of using wild rodents to monitor environmental pollution

- $\quad$ study and follow the population density of rodents in the region.

- $\quad$ study of morphological changes such as mutations that occur on the fur of mice.

- $\quad$ pathological studies of rodents (kidney, lung, liver, etc.) due to the presence of toxic substances in the environment.

- $\quad$ study of the deformities of some internal organs such as testis and sperm channels in males.

- $\quad$ study of the residues of radioactive materials as a result of the establishment of nuclear plants in some countries and the extent to which these residues affect the animals in general.

- $\quad$ study of skull bone abnormalities.

\section{Similar previous studies}

- individuation of murine species and analysis of their distribution on the area to be examined application of serological and bacteriological analyses on murine species in order to determine their role as vectors of zoonoses and use of mutage- 
netic tests (micronucleus test and sperm abnormality assay) in order to determine the effects on resident populations of chemical and/or radioactive pollutants present in the environment $[2,3]$.

- mammals might be considered better indicators and rodents' species are an obvious choice since they are exposed to many of the same influences as human beings [4].

- $\quad$ it is generally known that cadmium and lead are mainly accumulated in the hepatic tissue of animals [5]. So, some of them can be used potentially as pollution bio-indicator in the ecosystems. Such animal models allow us to evaluate potential human health risk associated with environmental contamination. With regard to the criteria described for the zoonotic diseases, free - living rodents such as brown rats in the urban systems are very ideal models to monitor pollution distribution, especially heavy metals. We found higher concentration of lead and cadmium in the liver of wild rats as well as sludge samples in the central parts of metropolitan Tehran in comparison with the northern parts. Similar results are also reported in other organisms such as Pinus eldarica by Mollashahi et al. [5] who found that zonal areas including no. 14 and 15 showed higher lead concentration.
- $\quad$ rat could be used potentially as a bio-indicator for heavy metal contamination in polluted metropolitans [2].

\section{Acknowledgement}

None.

\section{Conflict of Interest}

No conflict of interest.

\section{References}

1. Doungchawee G, Khoaprasert Y, Kongtim S, Thamavit W, Tajima K, et al. (2002) Use of Wild Rodents for Environmental Monitoring -Comparison of Rats in Bangkok and Rural Areas of Thailand. Asian Pacific Journal of Cancer Prevention 3(4): 367-368.

2. Hazratian L, Naderi M, Mollashahi M (2017) Norway rat, Rattus norvegicus in metropolitans, a bio-indicator for heavy metal pollution (Case study: Tehran, Iran). Caspian J Environ Sci 15(1): 85-92.

3. Ieradi LA, Cristaldi M, Maddeo D, Lillini E, NUT M (1992) Wild rodents of pontine islands as bioindicators of environmental quality. Hystrix (n.s.) 4(1): 41-49.

4. Moore MA, Tatematsu M (2001) Are the Phenotypes of Preneoplastic Lesions of Significance for Cancer Prevention? 1. Liver. Asian Pac J Cancer Prev 2(1): 27-42.

5. Mollashahi M, Alimohammadian H, Hosseini SM, Feizi V, Riahi A (2014) Mapping of Tehran air pollution by heavy metals using Morus alba leaves. Geography and Environmental Hazards 2(7): 69-84. 